\title{
RAÍZES POLÍTICAS DO BREXIT
}

Filipe Philipps de Castilho ${ }^{1}$

\begin{abstract}
Resumo
O trabalho pretende analisar de que forma uma noção de nacionalismo britânico, em contraste com a presença do Reino Unido dentro da União Europeia, levou os habitantes do Estado soberano insular ao sim no referendo do processo de saída do bloco econômico europeu, além de propor uma análise sobre a questão da percepção identitária britânica dentro do referendo de 2016. Foi realizada uma análise qualitativa e quantitativa da literatura acerca das teoria sobre o tema, em artigos, livros, jornais e sites, e pesquisas de opinião do Eurobarometer de 2013 até 2016; os dados foram colhidos e então analisados de maneira qualitativa e quantitativa, comparando resultados de pesquisas e literatura; assim, no intuito de verificar os efeitos de um fraco sentimento de pertencimento ao bloco aliado a um sentimento nacionalista e soberano, foi possível explicar o resultado do referendo, tendo como hipótese confirmada a maneira como a noção de soberania britânica, política, cultural e econômica levou ao voto favorável à saída do bloco, mostrando também como a xenofobia crescente dentro do Reino Unido foi um fator preponderante para a saída. Os resultados, além de tudo, ajudaram a explicar o papel idiossincrático e único do Reino Unido ao longo do tempo dentro da União Europeia, mostrando-se como outro elemento importante para a ruptura; por tratar-se de uma pesquisa desenvolvida quase simultaneamente ao processo, o trabalho mostra ineditismo. Pretende-se futuramente estudar os efeitos da saída enfim consumada nas questões de soberania e identidade dentro do Reino Unido, além das relações reformuladas com demais países da União Europeia.
\end{abstract}

Palavras-Chave: Brexit; Reino Unido; União Europeia; Soberania; Identidade.

\section{INTRODUÇÃO}

Constituído por Inglaterra, País de Gales, Escócia e Irlanda do Norte, o Reino Unido começou a fazer parte das comunidades europeias em 1973, após anos de recusa e de tratativas inconclusivas, somando-se então à Alemanha Ocidental, Bélgica, França, Itália, Luxemburgo e Países Baixos, fundadores do bloco econômico europeu. Adentrar ao bloco não significaria necessariamente um pertencimento de fato, visto que os britânicos sempre fariam questão de exercer uma participação de caráter idiossincrático e particular, derivada da herança de seu passado como grande império soberano. O imaginário popular britânico, principalmente dentro do viés conservador, seria pungente na percepção de povo muito mais britânica que europeia, que

\footnotetext{
${ }_{1}$ Universidade Federal do Paraná, philipps_filipe@ hotmail.com, https://orcid.org/0000-0001-6266-0934.
} 
conjuntamente com questões econômicas e políticas, desaguaria no referendo para a saída da União Europeia em 2016.

O presente trabalho se dividirá entre explicações sobre a formação da Comunidade Europeia e seus processos de integração, a explicação acerca das questões de soberania britânica e seu passado, a integração do Reino Unido no bloco europeu, a criação da União Europeia e as questões que resultariam na saída tempestuosa dos britânicos, contando com a análise da literatura do assunto, das pesquisas de opinião colhidas pelo Eurobarometer, de forma a explicar o pensamento dos britânicos à época, além de matérias de portais e jornais sobre os acontecimentos. A hipótese confirmada foi a que de fato a questão da soberania britânica foi, além de explicativa, o cerne do processo que deliberou no Brexit e na saída da União Europeia, tanto para com as instituições do Reino Unido, bem como para o imaginário cultural e social dos britânicos.

\section{A FORMAÇÃO DA COMUNIDADE EUROPEIA}

No final da Segunda Guerra Mundial os estados europeus encontravam-se ansiosos para encontrar uma forma de evitar novos embates de mesma estirpe. Ganhava escopo a análise funcionalista de que os nacionalismos extremos haviam levado a Europa à guerra e à destruição, sendo necessário construir instituições técnicas supranacionais e despolitizadas para gerir os recursos e administrar a cooperação entre os Estados europeus (JÚNIOR, 2020). A Europa Ocidental passaria a se enxergar então como uma entidade com interesses comuns, com mesmos ensejos econômicos; além disso, reconheceram que a recuperação de sua economia, devastada pelo conflito, só seria possível por meio de uma assistência dos Estados Unidos, o Plano Marshall, aliado a um processo de colaboração no desenvolvimento econômico entre os Estados europeus (SCOFIELD, 2018). Dentre os defensores do projeto de viés funcionalista estavam Robert Schumann e Jean Monnet, representando a França, e Konrad Adenauer, representando a Alemanha; a convergência desses pensadores residia na necessidade de limitar as soberanias nacionais para com isso fortalecer as instituições de integração europeias (JÚNIOR, 2020). Tal ideário iria de encontro ao conceito de convivência internacional de Kant, que procuraria criar uma maneira de superar o subjetivismo das soberanias, introduzindo a razão abrangente do ponto de vista da humanidade e do indivíduo como fim e não meio, visando a possibilidade da paz perpétua, o que encontraria eco em uma Europa ainda traumatizada pela guerra; a formulação kantiana encontraria 
escopo contemporâneo no artigo 11 do Pacto da Sociedade das Nações, cujo cerne diz respeito a indivisibilidade da paz, deixando claro que a guerra e os conflitos dizem respeito não apenas às partes diretamente envolvidas, mas a toda sociedade internacional (LAFER, 1995).

Em 1950, por meio da Declaração de Schuman, estabeleceu-se o marco inicial da integração europeia. Em 1951, por meio do Tratado de Paris, criou-se a Comunidade Europeia de Carvão e Aço (CECA) o primeiro estágio de integração do tipo, que tentou unir os mercados de carvão e aço de seus primeiros seis estados membros, sendo eles Alemanha Ocidental, Bélgica, França, Itália, Luxemburgo e Holanda; uma forma de evitar disputas econômicas severas por conta das matérias primas (COSTA, 2017). Com a Guerra Fria e a nova ordem econômica e ideológica sendo posta em plano mundial, outras organizações para cooperação e integração da Europa seriam instauradas e emergiriam entre os países. A União Europeia Ocidental (UEO) fundada em 1954, seria fundada visando o cenário militar; na frente econômica, para alocar os fundos do Plano Marshall seria criada a Organização para Cooperação Econômica Europeia (OEEC) em 1948, tornando-se a Organização para Cooperação e Desenvolvimento Econômico (OCDE) em 1961 (COSTA, 2017).

Em 1955, o Reino Unido seria convidado a integrar a CECA, recusando a oferta, pois a adesão, na visão dos britânicos, seria de certo modo uma forma de cessão e subtração de sua autoridade e soberania (SCOFIELD, 2018). A relação do Reino Unido com a construção europeia seria acidentada desde início, nunca partindo de uma vontade política real acerca de processos sobre a criação e participação em instituições supranacionais que restringissem de alguma forma sua soberania estatal. Na década de 1950, o Reino Unido recusar-se-ia a participar da OEEC. A hesitação britânica em assumir um papel central nos processos de integração seria sempre reforçada pela existência dos interesses comerciais e militares dos britânicos no continente europeu e fora dele; para o Reino Unido, os prejuízos da integração a longo prazo não compensariam, se comparados à estabilidade das relações com a Commonwealth e com os Estados Unidos.

Mesmo com o Congresso de Haia de 1948 servindo como o primeiro passo para uma convergência europeia cada vez mais estreita, Winston Churchill, que dirigiu os trabalhos do congresso, cuja deliberação seria a permissão acerca da criação do Conselho da Europa, justamente em Londres, no ano seguinte, apelaria à constituição de uma União entre os estados europeus sem a participação do Reino Unido (SOARES, 2019). O Reino Unido, em decorrência disso e também para equilibrar as forças, promoveria a criação de um contraponto à CECA. No dia 3 de maio de 1960, Suécia, Dinamarca, Áustria, Portugal, Reino Unido, Suíça e Noruega criariam a Associação Europeia de Livre-Comércio, com a intenção de fomentar o comércio mundial e o desenvolvimento 
de um mercado que abrangesse toda a Europa, com as barreiras comerciais sendo eliminadas e com o trânsito alfandegário facilitado; as transações comerciais entre os países da AELC seriam de pequeno volume, e a forma de associação simplificada facilitaria a migração dos países membros para a União Europeia (1960: FUNDAÇÃO..., 2020).

Em 1961, no entanto, ao reconhecer os benefícios econômicos da OEEC e com a piora das condições de comércio tanto com a Commonwealth como com os Estados Unidos, o Reino Unido iniciaria tratativas para sua adesão ao bloco, primeiro em 1961, depois em 1967. Entretanto, seu ingresso à organização internacional seria vetado nas duas tentativas pelo presidente da França, Charles de Gaulle, pois este enxergava uma forte aproximação dos britânicos com os Estados Unidos, o que poderia trazer instabilidade de forças ao bloco; a ideia do líder francês era não só limitar o projeto supranacional, mas também manter a liderança da França dentro do processo de integração regional na Europa; para isso, os britânicos deveriam, ao menos em princípio, permanecer fora do projeto de integração europeia (JÚNIOR, 2020). Somente após a saída do presidente francês em 1969 as negociações seriam retomadas, para que em $1^{\circ}$ de janeiro de 1973 os britânicos finalmente integrassem a OEEC (SZUCKO, 2018). Tais percalços demonstram e corroboram explicitamente a presença sempre errante e marcada por impasses do Reino Unido dentro das relações para com a integração europeia. É deveras importante ressaltar que os britânicos adentraram a um mercado comum, visando os laços econômicos, e não a um projeto de união política, o que poderá será visto com maior riqueza de detalhes quando da recusa dos britânicos em aderir elementos comuns aos países do bloco. O Reino Unido sempre fez questão de deixar clara sua intenção de evitar a construção de um grande bloco europeu unitário.

\section{UMA QUESTÃO DE SOBERANIA BRITÂNICA}

Para Lafer (1995), utilizando conceitos de Jean Bodin e Thomas Hobbes, a soberania poderia ser definida em função das seguintes características: absoluta, perpétua, indivisível, inalienável, imprescritível, podendo ser encarada, à maneira hobbesiana, como o agente público encarregado de eliminar, no território do Estado, a anarquia dos significados sobre o que é justo ou injusto prevalecente no estado de natureza; o objetivo estratégico do conceito de soberania seria o de consolidar a territorialidade do Estado moderno, resultante do histórico da centralização 
administrativa monárquica, do protecionismo econômico, dos exércitos permanentes e regulares e do cisma religioso na Europa. (LAFER, 1995).

De acordo com tais conceitos, a memória da centralidade e importância mundial do Reino Unido entre os séculos XVIII e XIX, do vasto e poderoso império britânico e da expansão colonialista nos séculos anteriores ainda teria uma grande influência na visão das elites políticas britânicas acerca da posição do país dentro da Europa, não sendo surpresa o sentimento de superioridade do país em relação ao resto da Europa (PERISIC, 2010). Vale ressaltar o caráter idiossincrático do modelo político do Reino Unido, dotado de Constituição não escrita, com noção de soberania definida pelo Parlamento, estruturas de poder centralizadas e unitárias, além uma cultura política contraditória dentro da esfera do Estado. Segundo Perisic (2010), para a ala 'saudosista' do extrato político e social, a vinculação com instituições europeias significaria perder parte da influência global e da importância própria e particular do Reino Unido, consistindo em uma barreira psicológica que explicaria a dificuldade sempre presente no relacionamento entre o Reino Unido e os blocos europeus.

Lafer (1995) enxerga a política internacional como a política do poder, caracterizando-se pela linha defendida pelo realismo contando com apenas dois atores - o diplomata e o soldado, que são os representantes da soberania, resultando daí o conceito elaborado por Maquiavel chamado de razão de Estado, ou seja, o não reconhecimento de uma ordem superior à qual o Estado e o seu soberano deveriam sujeitar-se na totalidade das suas manifestações. A razão de Estado, centrada na questão da sobrevivência da comunidade política no tempo e no espaço, afirma o subjetivismo da soberania, sendo o último grau de referência. Isso ajudaria a explicar a postura sempre reticente do Reino Unido e de seus líderes para com a integração europeia. Para atingir seus objetivos de integração, a União Europeia, desde sua gênese, procurou estabelecer um poder supranacional, direcionado à realização dos interesses da coletividade, sem proporcionar, no entanto, a perda da soberania dos Estados membros, mas buscando criar mecanismos restritivos no âmbito de decisões pertinentes ao processo de integração, como a delegação da soberania a uma instituição supranacional, visando reduzir os conflitos por meio da criação de tratados que pudessem dar ao conceito de soberania tons mais contemporâneos, sendo a soberania não mais uma propriedade indissolúvel do Estado, mas sim limitada pela interpendência, através de competências comuns e decisões compartilhadas; esse novo conceito de soberania poderia levar a conclusão de que a mesma pode ser exercida coletivamente (VOLPI, 2006). 
A necessidade do mútuo reconhecimento das soberanias, as exigências de cooperação através das organizações internacionais e o multilateralismo das colaborações, juntamente com o fato de as soberanias se verem permeadas pela ação transnacional, seriam elementos fundamentais para uma integração como a desejada pelas comunidades europeias, sendo esta realidade um limite à soberania por força da funcionalidade dos interesses (LAFER, 1995). Fatores que iriam de encontro ao defendidos pelos britânicos, zelosos de sua soberania e visão particular de autoentendimento.

Os ganhos econômicos advindos da entrada do Reino Unido não seriam os esperados, resultando em um referendo, em 1975, acerca da continuidade ou não no bloco econômico; tal referendo seria solicitado pelo Primeiro Ministro britânico Harold Wilson, do Partido Trabalhista inglês. Mudanças foram feitas para uma melhor adequação dos britânicos ao bloco, como um novo arranjo para a sua contribuição ao orçamento comunitário, redução dos preços do mercado agrícola, melhor acesso aos países da Commonwealth e ao mercado único, o que resultaria na continuidade, com 67\% da população britânica votando pela permanência na CEE (SCOFIELD, 2018), ocasionando uma mudança de tom mais favorável no posicionamento do Partido em relação à integração supranacional, assumindo assim um tom mais favorável; na mesma época, temáticas sociais começariam a ser abordadas pela legislação europeia, reforçando o tom amigável do Partido Trabalhista. (PERISIC, 2010).

\section{ENFIM A UNIÃO EUROPEIA: GÊNESE E ESTRUTURA}

Em fevereiro de 1992, o Tratado de Maastricht revisaria o Tratado de Roma, o que estabeleceria a o que hoje conhecemos como União Europeia, em uma clara evolução das formas e conteúdos da OEEC, contando agora com cooperação intergovernamental em política externa e de segurança, de justiça e assuntos domésticos, além de implementar a principal e mais sonora mudança, a adoção de moeda única, o Euro, lançado em 1999 e implementado em 2002. A UE se baseia no estado de direito, ou seja, seu funcionamento é operado e fundamentado através de tratados, que são acordados de forma voluntária e democrática pelos países membros do bloco. Dado o grau de parlamentarização constante da EU e da institucionalização do Conselho Europeu, hoje é possível descrever de maneira clara e peremptória o sistema institucional da UE como uma 
estrutura quadripartite. (COSTA, 2018). Importante compreender a estrutura do bloco para entender as deliberações advindas e o papel do Reino Unido.

QUADRO 1 - ESTRUTURA DA UNIÃO EUROPEIA

\begin{tabular}{|l|l|}
\hline PODER EXECUTIVO & PODER LEGISLATIVO \\
\hline $\begin{array}{l}\text { Conselho Europeu, que exerce o papel } \\
\text { semelhante a de um chefe de estado } \\
\text { coletivo }\end{array}$ & $\begin{array}{l}\text { Composto pelo Parlamento Europeu e pelo } \\
\text { Conselho }\end{array}$ \\
\hline $\begin{array}{l}\text { Comissão, que atua como um governo } \\
\text { e administração central (Comissão). }\end{array}$ & $\begin{array}{l}\text { Entendidos como câmara baixa e a câmara } \\
\text { alta em um parlamento dividido em dois } \\
\text { níveis. }\end{array}$ \\
\hline
\end{tabular}

FONTE: Costa (2017).

Já em dezembro de 1991, as duas conferências conseguem firmar o "Tratado da União Europeia" (TEU), também conhecido como Tratado de Maastricht, ativado de fato em fevereiro de 1992. Os estados membros desejavam preservar a aparência da unidade geral, mas não conseguiram introduzir novos objetivos de política externa, defesa, assuntos internos e justiça na estrutura da CEE. A estrutura do tratado possui três "pilares": a Comunidade Europeia, a Política Externa e de Segurança Comum (PESC) e a Cooperação em Justiça e Assuntos Internos (JAI). O Tratado de Maastricht também originou a União Econômica e Monetária (UEM), que além de instituir a moeda única, também ampliou os poderes do Parlamento Europeu e criou a cidadania europeia, podendo assim ser observado, segundo Costa (2018) uma "politização" dupla da integração europeia, por meio do exercício de poderes soberanos supranacionais reservados aos estados membros, e por meio da afirmação da natureza política do funcionamento da União. O Tratado de Maastricht e o Mercado Único entraram em vigor em 1993. Segundo Costa (2018) houve uma renovação dos debates entre as grandes teorias da integração europeia, que considera o período pós-Maastricht um período peculiar, considerando uma politização acerca da integração desde Maastricht, deliberando maior engajamento de públicos de massa e nos destaques das questões do bloco europeu em nível nacional, restringindo o curso e o conteúdo da integração conforme o espaço de manobra dos governos foi ficando mais limitado. O contexto pós-Maastricht seria caracterizado como 'um período de dissenso restritivo: os governos nacionais estão de mãos atadas no que diz respeito à solução das questões europeias, pois precisam considerar mais a opinião pública eurocética", (COSTA, 2018). A opinião pública eurocética teria papel fundamental das discussões que dariam ensejo ao Brexit.

O Reino Unido, por sua vez, sempre fez questão de exercer um papel idiossincrático para com a UE, dando continuidade ao que já fazia com a OEEC, ao escolher as matérias em que 
almejava obter maior integração com os outros países europeus e as quais desejava se abster. Em outubro de 1997 foi assinado o Tratado de Amsterdam, visando uma área de liberdade, segurança e justiça como novos objetivos da União Europeia. O Reino Unido não participou (SCOFIELD, 2018). Outro acordo a não contar com a participação dos britânicos foi o Acordo de Schengen, firmado em junho de 1990 com o objetivo de abolir os controles fronteiriços entre os estados membros da Comunidade, contando com vinte e seis países, dentre eles, vinte e dois membros da União Europeia. Mesmo sem a participação dos britânicos, o Espaço Schengen seria pauta da discussão futura acerca do Brexit.

Fortalecendo os compromissos do Tratado de Maastricht, em 1996 é estipulado o Pacto de Estabilidade e Crescimento, que especifica regras de coordenação para que os países orientem suas políticas orçamentais visando manter a estabilidade do bloco, contado com as obrigações de convergência econômica para a adesão da moeda comum. Em 2002, com a ativação do Euro, 12 países o adotam como moeda, sendo eles Bélgica, Alemanha, Grécia, Espanha, França, Irlanda, Itália, Luxemburgo, Holanda, Áustria, Portugal e Finlândia. O Reino Unido opta por não aderir, por meio de uma cláusula de não participação, mantendo maior distanciamento e autonomia frente às questões europeias (MCNABB, 2017).

O governo trabalhista de Tony Blair (1997-2007) apresentaria uma maior aproximação com a União Europeia, sendo cogitada a adoção do Euro como moeda oficial; devido a crises no bloco europeu, os planos de adoção da moeda única e a aproximação paulatina acabariam por perder espaço para novos movimentos eurocéticos (MCNABB, 2017). O euroceticismo não seria fenômeno recente, principalmente na antípoda ao Partido Trabalhista, visto que o período do governo Thatcher (1979-1990) teve como característica um forte isolamento político dos britânicos para com o resto da Europa; durante o período seria assinado o Ato Único Europeu, que contava com uma primeira intenção de formação de mercado interno europeu; todavia, Thatcher era contra tais medidas, ao entender que o Reino Unido perderia sua independência e sua soberania, opinião esta que já contava com a adesão do Partido Conservador; todos esses argumentos corroboram a ideia de que as ações políticas do Reino Unido encontram em seu cerne basilar o direcionamento fundamentado no nacionalismo britânico, nos ideais de soberania e na autonomia do país frente ao projeto de integração europeia (PERISIC, 2010). O fomento necessário aos eurocéticos.

\section{CAMINHOS QUE LEVAM AO BREXIT}


A ascensão do Partido UKIP (Partido da Independência do Reino Unido) é vital para entender o início do processo de desvinculação do bloco, pois seu crescimento acabaria por corroborar as vozes dos que sempre defenderam visões nacionalistas e "eurocéticas", sendo o UKIP a voz do avesso ao modelo supranacional europeu (JUNIOR, 2020) fugindo de tudo aquilo que pudesse limitar a soberania política britânica. O manifesto político do UKIP, datado de 1993, destaca a intenção de resgatar o controle da soberania britânica e de mecanismos que limitassem o poder da União Europeia em solo britânico, corroborando mais uma vez a defesa da soberania britânica em relação à integração europeia estabelecida no continente desde o Tratado de Maastricht. O movimento nacionalista britânico e o UKIP ganham força após a afirmação do tratado e dos vínculos e controles supranacionais (JUNIOR, 2020). Matéria da BBC de 2014 trata sobre a força adquirida do UKIP, construída ao longo do tempo e consolidada nas eleições daquele ano, ao destacar que o partido fez um esforço considerável para ampliar seu apelo, ao explicar como deixar a UE seria a resposta para toda uma série de questões dentro de uma pauta mais conservadora, ressaltando os 'problemas' sobre imigração, além de traçar planos para cortar impostos para os que têm renda média, além da oposição ao casamento gay; a mensagem do líder do partido Nigel Farage teria tocado os eleitores desencantados dos outros "três grandes partidos" (HUNT, 2014).

De acordo com Costa (2018) crises econômicas e financeiras, com os estados membros da União Europeia enfrentando uma situação econômica e social difícil, com pouco crescimento, alta taxa de desemprego e níveis elevados de déficit e dívida, e restritos pelos compromissos que assumiram com a Europa de buscar uma política de austeridade, acabaram por enfrentar a crescente insatisfação de seus cidadãos, com pacotes de resgate e medidas de austeridade impopulares, causando forte insatisfação para com a União Europeia; segundo o Eurobarometer de 2014, 63\% dos cidadãos consideravam a UE responsável pela austeridade das políticas econômicas, $42 \%$ dos europeus (+5 pontos percentuais desde a primavera de 2014) confiavam no Parlamento europeu, enquanto $43 \%$ (-5) desconfiavam do Parlamento; $42 \%$ dos habitantes do Reino Unido acreditavam em um futuro melhor fora da União Europeia, enquanto $37 \%$ dos entrevistados confiavam na União Europeia, com a desconfiança acerca do tema rondando os $50 \% .2$

Tal cenário levou à eleição de um grande número de Membros do Parlamento Europeu eurocéticos nas eleições de maio de 2014, levando também à ascensão de eurocéticos em pleitos

${ }_{2}$ https://ec.europa.eu/commfrontoffice/publicopinion/archives/eb/eb82/eb82_en.htm 
nacionais, variando de país para país, com os eurocéticos radicais de direita indo bem na Europa Ocidental e com a extrema esquerda mais bem-sucedida no Sul da Europa (COSTA, 2018).

Porém, seria em ambiente doméstico que tal cenário se faria mais pungente, nas eleições nacionais e locais, com os partidos eurocéticos se beneficiando do descontentamento de parte da população em relação à austeridade e ao processo de integração, juntamente com a pauta da migração e de outros temas sensíveis; no Reino Unido, o Partido da Independência do Reino Unido (UKIP) somou $27,5 \%$ dos votos.

Já nas eleições de 2019, os partidos de centro perderam maioria absoluta no Parlamento Europeu, enquanto os partidos liberais e verdes ganharam espaço, assim como os grupos de extrema direita e os eurocéticos, que triunfaram na Itália e na França; os partidos eurocéticos e de extrema direita, como o Agrupamento Nacional, de Marine Le Pen (França), Alternativa para a Alemanha (AfD) e a Liga Italiana, de Matteo Salvini, estão divididos em três grupos no Parlamento Europeu, com os blocos de extrema direita conquistando mais de $10 \%$ de representantes. Na França, o Agrupamento Nacional de Marine Le Pen mudou sua posição sobre a permanência da França na União Europeia, dizendo ser favorável pela permanência do país no bloco. (ELEIÇÕES PARA PARLAMENTO..., 2019).

No Reino Unido, o Partido do Brexit, lançado apenas seis semanas antes da eleição, ficou à frente mais uma vez dos tradicionais partidos Conservador e Trabalhista. O líder do grupo, Nigel Farage, afirmou que os dois principais partidos "poderiam aprender uma grande lição" com os resultados. Os Liberais Democratas, de orientação pró-europeia, ficaram em segundo lugar no Reino Unido (ELEIÇÕES PARA PARLAMENTO..., 2019).

\section{O TRATADO DE LISBOA}

Em junho de 2007, na cidade de Lisboa, os estados membros se reuniram para entrar em um consenso acerca de um tratado que trabalhasse com boa parte da Constituição da União, deixando de fora todas as disposições federalistas ou constitucionais, aumentando os poderes da UE, que passou a ter personalidade jurídica. O Tratado de Lisboa seria firmado em 13 de dezembro de 2007, alterando o Tratado da União Europeia e transformando o Tratado da CE no Tratado sobre o Funcionamento da União Europeia. 
O Tratado de Lisboa, que teria por objetivo finalizar a política institucional da União Europeia iniciada no Tratado de Maastricht, acabaria por conter um mecanismo no intuito de facilitar que um estado membro pudesse abandonar a UE, através do artigo 50. A saída de um Estado-Membro da UE sempre foi um tema recorrente no debate europeu; o Tratado de Roma, por exemplo, abordava apenas o processo de adesão de novos países, sem fazer qualquer tipo de referência ou direcionamento acerca da saída de algum membro. Sendo assim, o Tratado de Lisboa, muito além de finalizar os trabalhos iniciados pelo Tratado de Maastricht, veio a dar a possibilidade de os estados-membros poderem acionar e exercer o direito de saída da União, a partir de dezembro de 2009.

\section{ENFIM O BREXIT}

Em 2013, o Primeiro Ministro David Cameron declarou que o povo britânico deveria "se pronunciar" na Europa, ao prometer um referendo de entrada/saída caso os conservadores vencessem a eleição. O primeiro-ministro deixaria clara a intenção de renegociar o relacionamento e permanência do Reino Unido com a UE para depois dar aos britânicos a escolha entre permanecer ou sair da UE. A notícia seria bem recebida pelos eurocéticos que há muito faziam campanha pela saída do bloco, enquanto França e Alemanha advertiam que o Reino Unido não poderia simplesmente "escolher" a adesão à UE. Durante as acaloradas trocas de perguntas e sabatinas do primeiro-ministro no Parlamento, o líder trabalhista Ed Miliband acusou Cameron de estar "assustado" com o Partido da Independência do Reino Unido, que paulatinamente angariava mais e mais adesão (DAVID CAMERON PROMISES..., 2013).

David Cameron exigiria uma série de demandas visando um fortalecimento da soberania britânica perante o bloco, tais como o Reino Unido podendo impor limites nos benefícios sociais obtidos pelos imigrantes, maiores poderes ao Parlamento britânico, para que ele pudesse ter a prerrogativa de impedir a internalização de qualquer legislação comunitária, e que a União Europeia não tivesse uma política deletéria para com os Estados Membros que não adotassem o Euro como moeda. Também previa emendas em tratados para deixar claro que a cláusula feita aos países-membros de buscarem uma união cada vez mais próxima entre si não se aplicaria ao Reino Unido (UNIÃO EUROPEIA CHEGA A ACORDO..., 2016). 
Em fevereiro de 2016, uma minuta do acordo seria elaborada, concedendo ao Reino Unido um status especial no bloco; começariam então intensos debates e campanhas país afora acerca da permanência ou não no bloco; os defensores da saída tratavam de questões sobre a soberania do país, tais como a necessidade de o Reino Unido ter maior controle sobre suas fronteiras, visando proteger o sistema de seguridade social e empregos, através de um maior controle e diminuição de imigração, além de taxas comerciais mais vantajosas, alegando que as tarifas para com o bloco seriam desvantajosas, e ainda contando com as pressões exercidas por parlamentares do Partido Conservador e do UKIP, que defendiam o debate e consulta da população britânica sobre a saída ou permanência (SCOFIELD, 2018).

Já a favor da permanência, os defensores alegavam que a saída causaria impactos negativos na economia britânica, dificultando a imigração de britânicos para outros países membros da UE e ainda levaria à perda de diversas vagas de emprego, além de defenderem que os gastos e taxas para com a UE não seriam negativos frente aos inúmeros benefícios que o livre comércio e a participação no bloco traziam à nação (MCNABB, 2018).

Em 23 de junho de 2016 seria realizado o referendo, contando com uma participação de 71,8\% (30 milhões de pessoas) de eleitores, trazendo como resultado a confirmação de que a maioria dos cidadãos do Reino Unido de fato optava por abandonar a União Europeia. O Brexit recebeu $51,9 \%$ dos votos, enquanto $48,1 \%$ votaram pela permanência no bloco. Inglaterra e Gales apoiaram majoritariamente o Brexit, enquanto Londres, Escócia e Irlanda do Norte optaram pela permanência. Por conta do resultado e da crise iniciada no país, como uma queda vertiginosa da Libra Esterlina imediatamente após o resultado, o primeiro-ministro David Cameron anunciaria a renúncia do cargo (GUIMON, 2016).

O referendo revelaria uma profunda divisão de interesses nas diferentes regiões do Reino Unido. Além de a Escócia votar majoritariamente pela permanência, junto com a Irlanda do Norte e a região de Londres, outros fatores correlacionariam os votos, com destaque para o grau de escolaridade e a faixa etária.

Pessoas com mais de 65 anos tiveram duas vezes mais chances de votar pela saída da União Europeia do que as pessoas com menos de 25 anos. $70 \%$ dos eleitores cuja escolaridade seria apenas até a GCSE (uma qualificação acadêmica obtida em uma matéria especifica, geralmente por estudantes aos 16 anos de idade) ou menos votaram pela saída, enquanto 68\% dos eleitores com um diploma universitário votaram para permanecer na UE. Os menores de 25 anos tinham duas vezes mais chances de votar em permanecer (71\%) do que em deixar (29\%). Entre os maiores de 65 anos, 
o quadro é quase exatamente o oposto, já que 64\% dos maiores de 65 anos votaram por sair, enquanto apenas 36\% votaram em permanecer. Entre as outras faixas etárias, os eleitores de 24 a 49 anos optaram por permanecer (54\%) contra deixar (46\%), enquanto 60\% dos eleitores entre 50 e 64 anos optaram por deixar. 3

As tabelas, extraídas do site yougov, mostram de maneira mais detalhada os votos em porcentagem por partido, idade e grau de educação.

TABELA 1 - VOTOS EM PORCENTAGEM POR PARTIDO, IDADE E GRAU DE EDUCAÇÃO

\begin{tabular}{|l|l|l|}
\hline Partido & Permanecer & Deixar \\
\hline Conservador & 39 & 61 \\
\hline Trabalhista & 65 & 35 \\
\hline Liberal Democrata & 68 & 32 \\
\hline UKIP & 5 & 95 \\
\hline Verde & 80 & 20 \\
\hline
\end{tabular}

\begin{tabular}{|l|l|l|}
\hline Idade & Permanecer & Deixar \\
\hline $18-24$ & 71 & 29 \\
\hline $25-49$ & 54 & 46 \\
\hline $50-64$ & 40 & 60 \\
\hline $65+$ & 36 & 64 \\
\hline
\end{tabular}

\begin{tabular}{|l|l|l|}
\hline Educação & Permanecer & Deixar \\
\hline GCSE ou menor & 30 & 70 \\
\hline A Level & 50 & 50 \\
\hline Higher Below Degree & 48 & 52 \\
\hline Degree & 68 & 32 \\
\hline
\end{tabular}

FONTE: Yougov (2016).

É possível analisar, através das tabelas, que entre os eleitores dos partidos mais voltados à direita, como o Conservador e o UKIP, a taxa de votos para a opção de deixar a União Europeia foi massiva (61\% e $95 \%$, respectivamente), assim como entre os mais velhos (60\% de votos entre as pessoas com 50 até 64 anos e $64 \%$ para os com mais de 65) além de ser expressiva para com os de menor escolaridade, variando entre $70 \%$ dos que contavam apenas com o GCSE ou menos e 50\% entre os que contavam com o A-level (uma espécie de ensino médio britânico) e 52\% para os com ensino profissionalizante e/ou superior. Foi alta a taxa de jovens que optaram por permanecer, alcançando a expressiva porcentagem de $71 \%$ entre aqueles entre 18 e 24 anos, e $54 \%$ entre a faixa de 25 até 49 anos. Os partidos com viés de esquerda ou centro esquerda também registraram 
porcentagens mais altas para com a permanência, com o Partido Trabalhista registrando 65\% para a permanência, enquanto Liberal Democrata e Verde registraram 68\% e 80\% respectivamente. 68\% daqueles com o curso superior e diploma com honras (degree) votaram por permanecer na UE.

Fora da Inglaterra, o resultado do Brexit apresentou cenários díspares em diferentes regiões. Na Escócia, $62 \%$ dos eleitores votaram pela permanência e apenas 38\% pela saída, o que acabaria por dar ensejo ao ímpeto pela independência entre muitos escoceses. A Escócia acabara de passar por um plebiscito em 2014 que acabaria decidindo a permanência no Reino Unido, com um dos argumentos principais da campanha contra a independência sendo o acesso à União Europeia via Reino Unido. A Irlanda do Norte também votou pela permanência (55\% contra 44\%). O País de Gales votou pela saída (52,5\% contra 47,5\%) (PLEBISCITO REVELA..., 2016).

De acordo com estudo da Fundação Getúlio Vargas, áreas com menor concentração de imigrantes tiveram uma tendência pelo voto favorável a deixar a União Europeia. Ao isolar o quartil das áreas com maior crescimento da proporção de imigrantes entre 2010 e 2014, nota-se uma predominância do voto por deixar: $76,3 \%$ das áreas do quartil opinaram a favor da saída, assim como o quartil das áreas com maior desemprego, no qual 67,6\% delas votaram pelo Brexit. Os dados indicariam que a presença recente de imigrantes, conjuntamente com o baixo dinamismo do mercado de trabalho, pode ter contribuído para a posição favorável à saída da UE. 4

O contraste entre Londres e a maior parte da Inglaterra foi considerável, visto que na capital $60 \%$ votaram pela permanência e $40 \%$ pela saída. Essa diferença se explicaria em parte pela forte economia da cidade e pela maior presença de estrangeiros. Londrinos tenderiam a aceitar e a valorizar mais a globalização e a diversidade, estando mais acostumados a seus efeitos, positivos ou negativos (PLEBISCITO REVELA..., 2016).

Curiosamente, dados do Eurobarometer 85, de maio de 2016, mostravam que a maioria das pessoas no Reino Unido (53\%) dizia se sentir cidadã da UE, mais do que Itália (49\%), Bulgária (49\%) e Grécia (46\%). Já no Eurobarometer 86, de novembro de 2016, 48\% dos britânicos acreditavam em um futuro melhor fora da UE, contra $42 \%$ que não acreditavam nisso. Seguindo a tendência vista nos votos do referendo do Brexit, entre todos os europeus, respondendo a mesma questão sobre um futuro melhor ou pior fora da UE, a maioria dos entrevistados em todas as categorias sociodemográficas acreditava que seria mais fácil enfrentar o futuro dentro e não fora da UE, embora em graus variados, crença significativamente mais difundida entre jovens de 15 a 24 anos $(63 \%)$, estudantes (70\%), aqueles que estudaram até 20 anos ou mais (68\%) e aqueles que

\footnotetext{
${ }_{4}$ http://dapp.fgv.br/proporcao-de-imigrantes-no-territorio-influenciou-voto-pelo-brexit/
} 
nunca ou quase nunca tiveram dificuldades para pagar suas contas $(62 \%)$ do que entre os maiores de $55 \operatorname{anos}(54 \%)$, trabalhadores manuais (53\%), desempregados (47\% contra 39\%), aqueles que abandonaram a escola com 15 anos ou mais (48\% contra $38 \%$ ) e aqueles que lutam para pagar suas contas na maioria das vezes $(46 \%$ contra $41 \%)$.

\subsection{AS DELIBERAÇÕES DO REINO ‘DESUNIDO’}

De acordo com Soares (2018), a realização do referendo de 2016 sobre a saída do Reino Unido da União Europeia que resultaria no Brexit foi sujeita a fortes críticas, com correntes defendendo a ideia de que o voto popular não seria o modo adequado para decidir sobre um assunto de tamanha relevância, dada a alta complexidade técnica da decisão; as críticas veementes à convocatória do referendo sobre o Brexit incidiram sobre os riscos que esta iniciativa comportava para o papel das instituições políticas, no quadro de funcionamento da democracia representativa, sendo o resultado final favorável para a saída do Reino Unido da União Europeia via voto popular constituindo uma deriva ao princípio fundamental da democracia representativa, em virtude da ultrapassagem da supremacia do Parlamento britânico.

Em julho de 2016, após a renúncia de David Cameron, a também conservadora Theresa May assume o cargo de Primeiro Ministra, depois de aceitar o convite da rainha Elizabeth II para formar governo, com o desafio inicial de negociar a ruptura com o bloco e unir o Partido Conservador e um país profundamente dividido pelo Brexit; a primeira-ministra afirmaria à época que o Reino Unido teria um papel positivo e ousado fora do bloco europeu (THERESA MAY ASSUME..., 2016). A partir de então, diversos imbróglios desenrolariam um processo extremamente conturbado e denso para os britânicos.

Theresa May acionou o Artigo 50 do Tratado de Lisboa, mecanismo para a saída do bloco europeu, em 29 de março de 2017, iniciando as tormentosas negociações acerca da saída; uma das primeiras proposta do governo apresentada à UE passava por criar uma zona de comércio livre entre o Reino Unido e a União Europeia e defendia um mercado comum com alguma harmonização de regulamentação, o que para os membros conservadores do governo, apoiadores de um hardBrexit, ou seja, uma saída total e completa representava deixar o país exposto a fragilidades. A UE acabaria por também não aceitar o acordo.

Acabaria então por se iniciar uma discussão sobre a forma de saída, se através do Soft Brexit ou do Hard Brexit; o Soft Brexit seria a possibilidade de um acordo que mantivesse o Reino Unido 
estritamente alinhado com a União Europeia, mesmo com a saída do bloco. Os defensores desta abordagem acreditavam que desta maneira o impacto na economia e no orçamento britânicos não seria tão negativo depois da saída, com o Reino Unido podendo ter acesso tanto ao mercado único como à união aduaneira da União Europeia. O país continuaria a ficar ligado às normas e regulamentação europeias. O Hard Brexit rejeitaria totalmente a ideia de se manter um alinhamento com a União Europeia, ao colocar os direitos e interesses dos cidadãos britânicos em primeiro lugar, o que significaria para o Reino Unido perder privilégios exclusivos dos estados-membros, como perda de acesso pleno ao mercado único, à união aduaneira e à livre circulação de pessoas e bens; no entanto, também sem as pesadas regulamentações e tarifas do bloco, além de ter um controle total sobre as suas fronteiras e aplicar medidas de regulação mais rígidas, fora do princípio de Dublin e de outros tratados europeus que regulam a imigração e a livre circulação dentro do bloco, possibilitando o Reino Unido de fazer novos acordos comerciais e elaborar as suas próprias regras e procedimentos alfandegários (FRANCO, 2018).

Em 24 de maio de 2019, após diversas atribulações nas negociações, Theresa May renuncia ao cargo, ao se ver incapaz de conduzir o Reino Unido para fora da União Europeia; seu sucessor seria o também conservador Boris Johnson, que em seu discurso inicial afirmou que a saída do país da União Europeia sem acordo entre as partes seria uma possibilidade remota, reiterando que não desejava um "no deal”, uma separação sem pacto e sem fase de transição, dizendo acreditar ser possível alcançar um entendimento sem o envolvimento de controles alfandegários na fronteira irlandesa, visto que a do Norte é parte do Reino Unido, e a República ao sul, separada, seria paísmembro da UE (NEVES, 2019).

A fronteira entre as Irlandas sempre foi assunto de sensibilidade política, diplomática e de segurança, com a maior preocupação sendo a possibilidade de uma reinstauração de uma "fronteira dura", o que poderia colocar em risco o Acordo de Belfast de 1999, que colocou fim ao período de violência na Irlanda do Norte conhecido como The Troubles; isso fez com que negociadores do Reino Unido e da União Europeia costurassem uma solução conhecida como "backstop irlandês", visando garantir que a fronteira fosse mantida aberta em qualquer cenário de Brexit. No entanto, esse arranjo proposto pela ex-primeira-ministra britânica Theresa May não encontrou eco para com os parlamentares conservadores, que temiam que o Reino Unido ficasse preso ao bloco europeu por prazo indefinido, ou seja, sem a possibilidade de costurar acordos comerciais com outros países, o que acabou levando Theresa May a renunciar ao cargo. Com Boris Johnson, o "backstop irlandês" voltaria ao centro das discussões, visto que Johnson e o presidente da Comissão Europeia 
anunciaram um acordo cuja principal proposta para concretizar a saída seria a de abolir o mecanismo relativo à fronteira irlandesa. Ao remover esse expediente, Johnson esperava obter apoio de seu próprio partido e do DUP, partido norte-irlandês e um dos principais entraves para a aprovação do Brexit, que também não apoiou o acordo, afirmando que as mudanças não seriam "benéficas ao bem estar econômico da Irlanda do Norte" e dizendo que "vão fragilizar a integridade da União" (O CONFLITO HISTÓRICO..., 2019).

Mesmo com diversos percalços, como o acionamento de um mecanismo para encerrar o período de sessões do Parlamento, visando tirar o tempo para os grupos de oposição conseguirem bloquear via parlamento a possibilidade de saída do Reino Unido da União Europeia sem acordo (MIGUEL, 2019) além da convocação de novas eleições (e conseguindo uma vitória expressiva contra a oposiçãos), em 31 de janeiro de 2020 o país oficialmente abandona sua participação na União Europeia, com Boris Johnson declarando ser um "começo de uma nova era" para o país e prometendo uma "verdadeira renovação nacional" depois de 47 anos como membros do bloco europeu (BREXIT: REINO UNIDO...2020).

\subsection{E AGORA PARA ALGO COMPLETAMENTE DIFERENTE}

A confirmação de fato do processo não encerrou os traumas e problemas. $\mathrm{O}$ aumento de movimentos separatistas vindos de Escócia e Irlanda do Norte, que votaram contra o Brexit, tornouse expressivo. As dicotomias sociais e culturais aprofundaram uma grande divisão dentro do país, visto nas antinomias de opinião e votos variando entre os mais jovens e os mais velhos e entre as cidades e regiões. Outro imbróglio de proporções nababescas seria visto com a chegada da crise sanitária advinda do vírus da Covid-19; com todo o continente afetado pela pandemia, os impactos seriam fortemente sentidos no país, com mais de 30 mil mortes e mais de 200 mil infectados, dentre eles o próprio ministro Boris Johnson; mesmo não fazendo mais parte da União Europeia desde janeiro, o Reino Unido faria um período de transição até 31 de dezembro, tendo acesso aos mercados vizinhos. Um período de grandes incertezas, com a possibilidade de prorrogação do prazo de transição ou isolamento forçado sem acordo algum (SARMENTO, 2020).

\section{CONSIDERAÇÕES FINAIS}

${ }_{5}$ https://brasil.elpais.com/brasil/2019/12/13/internacional/1576215795_050013.html 
O papel sempre idiossincrático do Reino Unido dentro das integrações europeias foi de vital importância para explicar as deliberações que acabariam no Brexit. Desde a gênese dos processos de integração, o Reino Unido sempre tentou se manter à parte, seja optando por não fazer parte, como quando da criação do Tratado de Paris e da Comunidade Europeia de Carvão e Aço, seja imiscuindo-se de maneira particular e própria, ao adentrar em seus próprios termos na Comunidade Econômica Europeia e posteriormente na própria União Europeia. O papel histórico do Reino Unido na geopolítica mundial é deveras elucidativo no processo, visto que o caráter de protagonista global que o antigo Império Britânico exerceu ao longo de séculos deixou como legado uma noção de soberania e particularidade política exacerbada nas instituições britânicas e no imaginário popular, principalmente dentro de uma visão conservadora.

Com base nos dados colhidos e na literatura, fica visível que o sentimento dos britânicos de não pertencimento à unidade europeia não foi um fenômeno recente, sendo visto com ênfase desde o pós-guerra, passando por todos os processos de integrações, chegando até o referendo de 2016 . O crescimento de diversas pautas conservadoras fomentou o sentimento, como a questão da imigração, a xenofobia, o controle das fronteiras e a insatisfação para com as taxas econômicas.

As atribulações do processo de saída mesmo após o referendo positivo à saída em 2016 mostram como o processo foi marcado por diversas dicotomias e divergências acerca de questões e percepções de identidade dentro das visões de pertencimento britânico e europeu, atestados pelas pesquisas do Eurobarometer, e dentro das questões econômicas e de soberania, vistas inclusive no próprio Partido Conservador, cujas divergências acabariam por causar a renúncia de dois primeirosministros.

Mesmo com a saída já formalizada, o processo parece longe de um fim, visto que o arrependimento de grande parte da população nota-se crescente, com um parcela da população que optou pelo sim sentindo-se enganada durante o processo, além de questões como a crise econômica e social advindas da pandemia da Covid-19 mostrando-se vitais para os acordos dos processos de saída, com a integração do bloco econômico europeu sendo o cerne da recuperação do continente. O agora para algo completamente diferente mostra-se cada vez mais no campo do depois. 


\section{REFERÊNCIAS}

1960: Fundação da Associação Europeia de Livre-Comércio. DW BRASIL. 03 de maio de 2020. Disponível em: https://p.dw.com/p/1JIm; Acesso em 05/12/2020.

BARROS, A. R. DE. O conceito de soberania no Methodus de Jean Bodin. Discurso, v. 27, n. 1, p. 139-155, 9 jun. 1996.

BREXIT: Reino Unido oficialmente deixou a União Europeia - O que acontece agora? BBC BRASIL. 31 de jan. de 2020. Disponível em: https://www.bbc.com/portuguese/internacional51335145 ; Acesso em 11/05/2020.

COSTA, Olivier. A União Europeia e a sua política exterior. Brasília, FUNAG, 2017.

DAVID Cameron promises in/out referendum on EU. BBC. 23 de jan. de 2013. Disponível em: https://www.bbc.com/news/uk-politics-21148282 ; Acesso em 15/12/2019.

ELEIÇÕES para Parlamento Europeu: quem são os ganhadores e perdedores e o que isso representa. BBC BRASIL. 27 de maio de 2019. Disponível em : https://www.bbc.com/portuguese/internacional-48420794; Acesso em 13/12/2019.

FRANCO, Ana Sofia. Hard, soft ou no deal? Um guia para perceber o Brexit. ECO. 02 de set. de 2018. Disponível em: https://eco.sapo.pt/descodificador/hard-soft-ou-no-deal-um-guia-paraperceber-o-brexit/04-quais-sao-os-cenarios-possiveis-do-acordo-com-a-ue/; Acesso em 20/02/2020.

GEORGE, Stephen. British Policy in the European Community: the commitment to globalism. University of Sheffield, UK, 1991.

GUIMON, Pablo. 'Brexit' vence e Reino Unido deixará a União Europeia. EL PAÍS. 24 de jun. de $2016 . \quad$ Disponível em: https://brasil.elpais.com/brasil/2016/06/24/internacional/1466741749_403437.html ; Acesso em $11 / 02 / 2020$.

HUNT, Alex. UKIP: The story of the UK Independence Party's rise. BBC. 21 de nov, de 2014. Disponível em: https://www.bbc.com/news/uk-politics-21614073; Acesso em 11/12/2019.

JÚNIOR, Helvécio Jesus. O Brexit, a soberania e o globalismo. Boletim de Conjuntura (BOCA), Boa Vista, v. 1, n. 2, p. 24-27, fev. 2020.

LAFER, Celso. A soberania e os direitos humanos. Lua Nova, São Paulo, n. 35, p.137-148, 1995. 
LUZ, Margareth da; OLIVEIRA, Wagner; FERNANDES, Janaina de Mendonça; BARBOSA, Bárbara; GRAÇA, Luís Felipe G. da. Proporção de imigrantes no território influenciou voto pelo Brexit. FGV DAPP, São Paulo, 2016.

MCNABB, Carolina Vanzato. A saída do Reino Unido da União Econômica e Monetária Europeia (Brexit): Uma avaliação a partir das crises recentes e da instabilidade interna do bloco. 2018. 35 f. Trabalho de Conclusão de Curso (Graduação em Relações Internacionais) Universidade Federal de Uberlândia, Uberlândia, 2018.

MIGUEL, Rafa de. Boris Johnson desafia a oposição e suspende o Parlamento de surpresa . EL PAÍS. 28 de ago. de 2019. Disponível em: https://brasil.elpais.com/brasil/2019/08/28/internacional/1566983159_822606.html; Acesso em: $17 / 01 / 2020$.

MIGUEL, Rafa de. Boris Johnson consegue maioria arrebatadora e tem caminho livre para aprovar Brexit. EL PAÍS. 13 de dez. de 2019. Disponível em https://brasil.elpais.com/brasil/2019/12/13/internacional/1576215795_050013.html . Acesso em: $17 / 01 / 2020$.

NEVES, Lucas. Boris Johnson assume como premiê e diz que brexit sem acordo é possibilidade remota. FOLHA DE SÃO PAULO. 24 de jul. de 2019. Disponível em : https://www1.folha.uol.com.br/mundo/2019/07/em-1o-discurso-boris-johnson-ve-brexit-semacordo-como-possibilidade-remota.shtml; Acesso em 04/05/2020

O CONFLITO histórico com a Irlanda que ameaça acordo do Brexit. BBC BRASIL. 17 de out. de 2019. Disponível em: https://www.bbc.com/portuguese/internacional-50091640; Acesso em 10/02/2020.

PLEBISCITO revela 'Reino Desunido' e fosso entre gerações. BBC BRASIL. 24 jun. 2016. Disponível em: https://www.bbc.com/portuguese/internacional-36617121; Acesso em: 14/12/2017 PERISIC, Bojana. Britain and Europe: a history of difficult relations. Institute for Cultural Diplomacy, Berlin, March 2010.

SARMENTO, Claudia. Brexit e pandemia do coronavírus embolam futuro do Reino Unido. $\mathrm{O}$ GLOBO. 10 de mai. de 2020. Disponível em: https://oglobo.globo.com/mundo/brexit-pandemia-docoronavirus-embolam-futuro-do-reino-unido-24419801; Acesso em 14/05/2020. 
SCOFIELD, Ana Clara Balda. As especificidades da relação entre o Reino Unido e a União

Europeia: desde a adesão ao bloco às suas futuras relações após o Brexit. FGV, Rio de Janeiro, 2018.

SOARES, António Goucha. Brexit: O referendo de 2016. Relações Internacionais, Lisboa , n. 61, p. 63-75, mar. 2019.

SZUCKO, A. S. Percepções Identitárias no Reino Unido: Antes e depois do referendo Britânico. Carta Internacional, v. 13, n. 1, 16 maio 2018.

THERESA May assume como premier do Reino Unido. O GLOBO. 13 de jul. de 2017. Disponível em: https://oglobo.globo.com/mundo/theresa-may-assume-como-premier-do-reinounido-19703815; Acesso em 05/05/2020.

UNIÃO Europeia chega a acordo sobre demandas do Reino Unido. G1. 20 de fev. de 2016. Disponível em: http://g1.globo.com/mundo/noticia/2016/02/ue-chega-a-acordo-sobre-demandasbritanicas.html; Acesso em 13/10/2019.

VOLPI, Almir. Desafios políticos da União Europeia. Tese de doutoramento. Departamento de Ciências Sociais. Pontifícia Universidade Católica de São Paulo, São Paulo, 2006.

YOUGOV. How Britain voted at the EU referendum. 27 de junho de 2016. Disponível em : https://yougov.co.uk/topics/politics/articles-reports/2016/06/27/how-britain-voted; Acesso em 20/04/2020. 